the so-called big number coincidences or the varying $G$ theories, have occupied the attentions of eminent physicists and astronomers. One should not blame the author for attempting a comprehensive presentation of such issues just because they command only minority support.

My real criticism of this book is that it reads rather like a shopping list. In his enthusiasm for including everything, the author has only managed to achieve a compendium of speculations, and not a coherent discussion. References are so liberally used that the text becomes impossible to read in some parts. On one page I counted one hundred such interjections. This is fine in a reference source for non-standard cosmology and astrophysics, but will not satisfy the demand by conservative "straight thinkers" to know something of the work of their more adventurous-minded colleagues.

Of course, a subject does not become respectable merely by quoting a vast array of big names. Even Einstein patronized some odd theories. Nor should one be persuaded that all unconventional ideas are in some mysterious way consistent with each other. This book is written in a style that leads one to believe there is a sort of grand, coherent theory of unconventional physics and cosmology existing alongside the more publicized one. It gives the impression of two sciences: the one to which most professionals subscribe, and another, almost the same in its predictions, but with subtle differences. Wesson is fair in drawing attention to some of the shortcomings of the latter, but clearly believes that his several hundred "grey area" references are probing closer to the truth than many of us would be prepared to acknowledge.

Paul Davies is Professor of Theoretical Physics at the University of Newcastle upon Tyne.

\title{
Agricultural prognoses
}

\section{Kenneth Blaxter}

Britain's Future in Farming. Edited by Sir Frank Engledow and Leonard Amey. Pp.164. (Geographical Publications: Berkhamsted, Herts, UK, 1980.) £9.

THE farming industry accounts for less than $3 \%$ of the labour force in the United Kingdom and contributes about the same percentage to its gross domestic product. Yet it is the most obvious of our industries since it occupies the major part of our countryside and produces most of the food we consume. The industry has much changed with time; it is now capital intensive and heavily dependent in some of its sectors on sophisticated inputs from other parts of the economy. These changes are relatively recent and, as the authors of this book state, "a highly urbanized economy with a romantic view of the countryside has yet to come to terms with the unpicturesque aspects of an intensive and efficient agriculture'". Questions necessarily arise about the future of farming, in turn inevitably implying questions about the policy to be adopted and the goals to be sought; these considerations are basic to this volume.

The book is the result of four years of study by a group of 15 people knowledgeable about farming, food provision, forestry, agricultural science, banking, and the social and political history of land use. None of the chapters is assigned to an author, but the discerning can detect where initial responsibility rested for written styles are revealing. There is thus a collective responsibility and this at times seems to have engendered some collective irresponsibility. Surely some of the statements made cannot have been agreed by all. Is it reasonable to suppose that all agreed "that the Ministry of Agriculture [MAFF] should resume its role in education and research and subsume the Agricultural Research Council [ARC]"? Or that security of tenure for farmers should be withdrawn forthwith? Such statements in the text do not appear in the conclusions with which no doubt all agreed. The first becomes transformed to a plea for better integration and a suggestion that attention should be drawn to the relationship of MAFF and ARC, while the second does not appear at all.

A few provocative statements, however, do not detract from the overall thesis and, on the contrary, perhaps enhance what is a sensible account of the problems related to the management of our resources of land. It should do much to show that the interests of agricultural and urban communities in reality have much in common and that certain broad principles related to land use may well be sufficient to provide a basis on which to develop policies to meet new eventualities. The conclusions and recommendations are admittedly detailed - there are 28 of them - but the whole tenor of the book relates to the theme that the source of renewable land must be preserved, that the pressures upon it whether direct or indirect must be reduced and farming practices themselves should be designed to provide a flexibility to accommodate inevitable and continued change.

Sir Kenneth Blaxter is Director of the Rowett Research Institute, Aberdeen.

\section{Practical vacua}

\section{John Yarwood}

A User's Guide to Vacuum Technology. By John F. O'Hanlon. Pp.402. (WileyInterscience: 1980.) $£ 13.35, \$ 31.20$.

JOHN O'Hanlon is a member of the research staff at IBM in the USA. As a result this book is really up-to-date. He has written the most useful and thoughtful account of vacuum technology which has appeared in recent years, and one which will be of value to the student, technician, engineer, scientist and technical manager. As would be expected from an author with such a background, the book (according to his preface) emphasizes "the operation and selection of equipment for processes used in semiconductor, optics, and related technologies". But he does himself an injustice - this book is much wider in scope than such a statement would appear to indicate.

SI units are used throughout, with the exception that pumping speed (now called "volume rate of flow" - not a good term although scientifically accurate) is given in $1 / \mathrm{s}$ or $\mathrm{m}^{3} / \mathrm{h}$, depending on the type of pump, and the diameters of the top flanges of diffusion pumps are given in inches. The section on essential gas theory covers gas properties, kinetic theory, basic relevant formulae (without proofs), gas flow and the measurement of pumping speed (where the work of the International Standards Organization has not been acknowledged; all the credit seems to go to the USA). Succeeding chapters are up-to-date, apposite accounts of real value, dealing with a wide range of equipment - gauges, pumps, analysers - and associated topics.

The book is rounded off with six appendices and, overall, can be recommended as a most useful and comprehensive volume.

John Yarwood was formerly Head of Physics at the Polytechnic of Central London, and is the editor of Vacuum.

\section{UV photobiology}

\author{
Philip C. Hanawalt
}

Biological Effects of Ultraviolet Radiation. By Walter Harm. Pp.216. (Cambridge University Press: 1980.) Hbk £15, \$29.95; pbk £4.95, \$9.95.

WF HAVE long appreciated the essential role that light plays in the maintenance of life forms on our planet through the processes of photosynthesis. In recent years, however, we have become increasingly aware of the deleterious effects of the shorter wavelengths of light in the Sun's spectrum. We have learned that ultraviolet 